ТЕМА НА БРОЯ - РЕТИНА

HOT TOPIC - RETINA

\title{
STANDARDIZATION OF OCT ANGIOGRAPHY NOMENCLATURE IN RETINAL VASCULAR DISEASES: FIRST SURVEY RESULTS
}

\author{
M. Munk, A. Kashani \\ University Eye Clinic, Bern, Switzerland
}

\begin{abstract}
Purpose. To develop a consensus nomenclature for OCT angiography (OCTA) findings in retinal vascular diseases. Design. Online survey using the Delphi Method. Participants. Members of The Retina Society, the European Society of Retina Specialists, and the Japanese Retina and Vitreous Society. Methods. An online questionnaire on OCTA terminology in retinal vascular diseases was sent to members of The Retina Society, the European Society of Retina Specialists, and the Japanese Retina and Vitreous Society. The respondents were divided into 2 groups ("experts" vs. "users") according to the number of their publications in this field. The respondents who had more than 5 publications in the field of OCTA and retinal vascular diseases were considered the OCTA "experts" group. Main Outcome Measures Consensus and near consensus on OCTA nomenclature. Results. The complete responses of 85 retina specialists were included in the analysis. Thirty-one were categorized as "experts." There was a consensus in both groups that OCTA parameters such as foveal avascular zone (FAZ) parameters, areas of nonperfusion, and presence of neovascularization (NV) should be implemented in the identification and staging of diabetic retinopathy (DR) and that OCTA can be applied to differentiate between ischemic and nonischemic retinal vein occlusion (RVO). Diabetic macular ischemia (DMI) also can be assessed via OCTA. Further, there was consensus that the terminology should differ on the basis of the underlying causes of decreased vascular flow signal. There was disagreement in other areas, such as which terms should be applied to describe decreased OCTA signal from different causes, the definition of wide-field OCTA, and how to quantify DMI and area of decreased flow signal. These discrepancies form the basis for the upcoming expert Delphi rounds that aim to develop a standardized OCTA nomenclature. Conclusions. Although there was agreement in some areas, significant differences were found in many areas of OCTA terminology among all respondents, but also between the expert and user groups. This indicates the need for standardization of the nomenclature among all specialists in the field of retinal vascular diseases.
\end{abstract}

Key words: OCT angiography, retinal vascular disease, diabetic retinopathy, retinal vein occlusion, Delphi

\section{СТАНДАРТИЗАЦИЯ НА ОСТ-А НОМЕНКЛАТУРАТА ПРИ СЪДОВИ ЗАБОЛЯВАНИЯ НА РЕТИНАТА - ПЪРВИ РЕЗУЛТАТИ}

\author{
М. Мунк, А. Кашани \\ Университетска очна клиника, Берн, Швецария
}

Резюме. Цел. Да се разработи консенсусна номенклатура за обективна диагностика на ОСТ ангиография (ОСТА) при съдови заболявания на ретината. Проект - онлайн проучване, използвайки метода Delphi. Участници. Членове на Ретиналното общество, Европейското дружество на специалистите по ретина и Японското общество на ретината и стъкловидното тяло. Методи. Онлайн въпросник за терминологията на ОСТА при съдови заболявания на ретината беше изпратен на членовете на Ретиналното общество, Европейското дружество на специалистите по ретина и Японското общество на ретината и стъкловидното тяло. Участниците бяха разделени на 2 групи („експерти“ срещу „потребители“) според броя на техните публикации в тази област. Участниците, които са имали повече от 5 публикации в областта на ОСТА и съдовите заболявания на ретината, се считат за групата „експерти“ на ОСТА. Основни крайни цели - Консенсус и почти консенсус относно номенклатурата на ОСТА. Резултати. Пълните отговори на 85 специалисти по ретината бяха точно анализирани. Тридесет и един бяха категоризирани като „експерти“. Имаше консенсус и в двете 
групи, че параметрите на ОCTA, като параметрите на фовеалната аваскуларна зона (FAZ), зоните на неперфузия и наличието на неоваскуларизация (NV) трябва да бъдат приложени при идентифицирането и поставянето на диагнозата диабетна ретинопатия (DR) и че ОСТА може да се прилага за разграничаване на исхемична и неисхемична оклузия на ретиналната вена (RVO). Диабетната макулна исхемия (DMI) също може да бъде оценена чрез ОСТА. Освен това имаше консенсус, че терминологията трябва да се различава в зависимост от основните причини за намален сигнал в съдовия поток. Имаше разногласия в други области, като например кои термини трябва да се прилагат за описване на намален ОСТА сигнал от различни причини, дефиницията на ОСТА с широко поле и как да се определи количествено DMI и площта на сигнала с намален поток. Тези несъответствия формират основата за разработването на стандартизирана ОСТА номенклатура. Изводи. Въпреки че имаше съгласие в някои области, бяха открити значителни различия в много области на терминологията на ОСТА сред всички участници, но също и между експертните и потребителските групи. Това показва необходимостта от стандартизация на номенклатурата сред всички специалисти в областта на съдовите заболявания на ретината.

Ключови думи: ОСТ ангиография, съдово заболяване на ретината, диабетна ретинопатия, оклузия на ретиналната вена, Delphi

OCT angiography (OCTA) has become an essential imaging modality in the diagnosis and follow-up of retinal vascular diseases. OCTA generates 3-dimensional depth-resolved images of retinal and choroidal vasculature $[1,2]$. This nascent technology is fast, dye-free, and noninvasive, and can provide transverse and en face images to detect and localize vascular flow abnormalities and to present structural and perfusion information all at once. OCTA can detect blood flow in the superficial, middle, and deep retinal capillary plexus, as well as in the choriocapillaris and choroid.

OCTA provides a tool by which we can expand our understanding of retinal vascular diseases. In many cases, OCTA has already advanced our appreciation of clinical and physiologic phenomena that were not previously known or detectable. However, there is no consensus to date on the OCTA terminology, and there are numerous, disparate, and often contradictory terms used to describe OCTA findings in the literature. For example, Dodo et al3 used "flow void" to describe the absence of retinal and choroidal capillary flow signal in eyes with diabetic retinopathy (DR) on OCTA scans, whereas Nesper et al. [4] and Tian et al. [5] used the term "capillary nonperfusion." Kashani et al $[6,7]$ and Kim et al. [8]used the term "impaired capillary perfusion" to indicate the possibility of altered perfusion without complete absence of perfusion. Other terms such as "grayish areas," "no-flow areas," and "areas with decreased vascular perfusion" have been seen in publications $[9,10]$. Additional terms such as "flow deficit," "flow attenuation," "low and no flow," "reduced flow," "flow abnormalities," and "flow void" are interchangeably used in current literature $[9,10,11,12]$. The underlying causes of flow attenuation should be considered when using these various terms. Flow signal attenuation due to ischemia and capillary dropout should be differently termed than flow attenuation because of the presence of macular edema and displacement of retinal vessels, respectively. Slow, nondetectable flow present in microaneurysms should be differentiated as well. Terms to quantify decreased vascular flow on OCTA are also heterogeneously used and assessed. "Intercapillary regions," "flow density," "perfusion density," "vessel density," and "capillary dropout density" are interchangeably applied in recent articles, and definitions are inconsistent.

Nomenclature describing quantification of these various OCTA-based capillary nonperfusion measures are also confusing. For example, perfusion density was defined as the percentage area occupied by perfused binarized vessels in some publications, whereas the same measurement was defined in some other studies as vessel density [10]. The manufacturer software of Zeiss Angioplex uses the term "vessel density" to quantify the total length of skeletonized perfused vasculature per unit area in a region of measurement (unit: $\mathrm{U} / \mathrm{mm}$ ), whereas Optovue uses the term "vessel density" to describe the total area of perfused vasculature per unit area in a region of measurement (unit: \%). In contrast, the Zeiss software uses the term "perfusion density" to describe the latter assessment.

In addition to this inconsistency, OCTA manufacturer software does not allow the homogenous 
assessment of 1 single quantitative OCTA parameter across different machines. Although Zeiss Angioplex offers the analysis of perfusion density, vessel density, and different foveal avascular zone (FAZ) parameters such as circularity, size, and area, Optovue enables the assessment of the vessel density, flow, and nonflow area assessment and different FAZ parameters such as FAZ area, perimeter, and AI/FD (circularity index/FD-300 [vessel density $300 \mu \mathrm{m}$ from the fovea]). Other commercial software only allows the manual assessment of the FAZ area so far.

Until now, the FAZ area is the most consistently assessable parameter across al. OCTA software. However, some devices allow FAZ area assessment only in the superficial slab, whereas others enable assessment only in the whole retina slab. This inhomogeneity leads to the use of nonvalidated third-party software such as Image J. In addition, various parameters must be manually adjusted for each software version, such as threshold, contrast, sharpening, color balance, and denoising, which makes the comparison among different studies and assessments unreliable.

Variable segmentation strategies of the superficial and deep capillary plexus add to the heterogeneity. Although some algorithms use the middle of the inner nuclear layer as the boundary (e.g., Optovue), others use the top of the inner nuclear layer (e.g., Topcon) [6].

All these issues make the homogenous description and collection of OCTA data impossible. Consensus terminology would not only help simplify and consolidate these terms but also improve accuracy of the measurements and quantification.

It is our aim to establish a consensus nomenclature for OCTA findings in the field of retinal vascular diseases. This article describes the first step to develop the latter using a Delphi Method and presents the consensus results of an electronic survey carried out among the members of the Japanese Retina and Vitreous Society, The Retina Society, and the European Society of Retina Specialists. It will be followed by expert Delphi rounds, which aim to reach consensus for parameters and questions in which no initial majority agreement could be reached.

\section{METHODS}

We conducted a literature search via PubMed database for articles written in English in the field of retinal vascular diseases and OCTA. We comprehensively reviewed the literature to explore and collect all commonly used terms to describe OCTA blood flow information in the en face OCTA and cross-sectional OCTA B-scans. This was the basis of an electronic survey consisting of 33 questions and 5 main categories. This survey was compiled via an online platform (Survey Monkey) and included general questions on OCTA and wide-field OCTA imaging, OCTA terminology of vascular flow alterations, terminology for retinal neovascularization (NV), the use of OCTA in retinal vascular diseases management and artifacts terminology in en face OCTA, and cross-sectional OCTA B-scans [28]. The complete survey is shown in Table S1 (available at www. ophthalmologyretina.org). Institutional Review Board was not required. All research adhered to the tenets of the Declaration of Helsinki. All participants provided informed consent.

The questionnaire was sent to members of The Retina Society, the European Society of Retina Specialists, and the Japanese Retina and Vitreous Society from May to August 2020 via an online link. Personal information could be provided, but there was also the option to remain anonymous. All attendees were asked to indicate the number of publications in the field of retinal vascular diseases and OCTA, and an estimate of OCTAs they are usually evaluating in the clinic per week. Based on their expertise, respondents were divided into 2 groups: "user" and "expert" groups. 8 The expert group was defined by 5 or more publications in this field, and the remaining participants were categorized as "OCTA users" [8].

To start, the guidelines for wide-field imaging of the International Wide-field Imaging Study Group were used for defining the wide-field imaging in OCTA [29]. As a basis for defining retinal $\mathrm{NV}$, the recommended, mutually agreed definitions of (neovascularization elsewhere [NVE]/ neovascularization at the disc [NVD]) on the cross-section and OCTA en face scans were use. 
To describe and define OCTA artifacts, the following terms were used, all regularly used in respective literature and by experts:

- Motion artifact: image artifact caused by eye movement during image acquisition

- Projection artifact: the artificial appearance of flow in deeper retinal layers

- Segmentation artifact: artifact caused from improper segmentation by software after image acquisition has been completed

- Blink artifact: artifact caused by the patient blinking during imaging

- Shadowing artifact: artifacts caused by media opacity or hemorrhage during imaging that appears as areas of decreased flow information on the structural en face and the en face OCTA slabs.

Based on prior experience with the Delphi method, the general agreement within a group must be assessed [3]. Agreement threshold is usually set at $60 \%$. Thus, consensus was defined by an agreement of $\geq 60 \%$ in this article. Near consensus was achieved in the case of $51 \%$ to $60 \%$ agreement, and no consensus was defined by a $<51 \%$ agreement. The term "agreement" refers to the consensus among the members of the "users" group or the "experts" group.

\section{RESULTS}

Overall, 164 retina specialists took part and 88 specialists completed this online survey. Some $96.6 \%(n=85)$ of them owned an OCTA machine, and $3.4 \%(n=3)$ did not and were also excluded from further analysis. Of these 85 participants, 31 (26\%) were considered experts with $\geq 5$ publications in the field.

\section{OCTA Wide-field Imaging}

A consensus among the users group (66.67\%) was obtained that the current definition of widefield imaging (the visualization of all 4 vortex veins) cannot be transferred to OCTA in retinal vascular diseases. However, only $51.61 \%$ of the experts agreed on this.

Near consensus was achieved based on which parameter wide-field OCTA imaging should be used to designate. Some $58.33 \%$ of the users group versus $43.75 \%$ of the experts group agreed that the degrees of field of view (FOV) should be the determining factor. There was near consensus among the experts group $(57.14 \%$ vs. $42.86 \%$ of the users group) that an FOV of $\geq 120^{\circ}$ should be considered as wide-field OCTA (Fig 1).

\section{Measurement of Decreased Vascular Flow on Conventional and Wide-field OCTA}

Some $74.19 \%$ of the OCTA experts group thought that automatic measurement in square millimeters using manufacturer software should be the method of choice for the assessment of areas of decreased flow. An area of $>0.5 \mathrm{~mm}^{2}$ was proposed by $57.69 \%$ of the experts group (53.49\% of the users group) to be considered as a "large area of decreased flow" on conventional OCTA (Fig 2).

Some $59.26 \%$ of the users group $(51.61 \%$ of the experts group) thought that decreased flow on
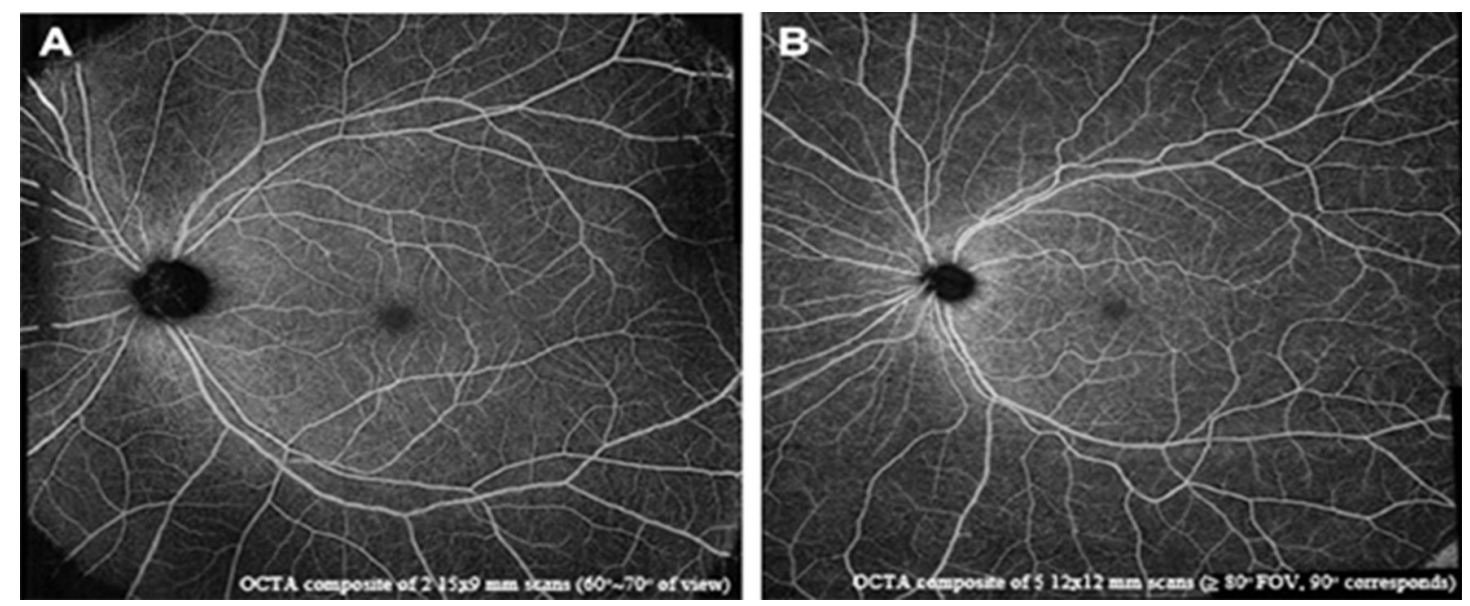

Fig. 1. Near consensus was achieved to define wide-field OCT angiography (OCTA) based on field of view (FOV). Montage OCTA of the posterior pole in a normal patient (superficial plexus scan) showing a $70^{\circ} \mathrm{FOV}$ (composite of 2 images of $15 \times 9 \mathrm{~mm}$ ) $(\mathrm{A})$ and $90^{\circ}$ of FOV (5 images of $12 \times 12 \mathrm{~mm}$ ) (B) 

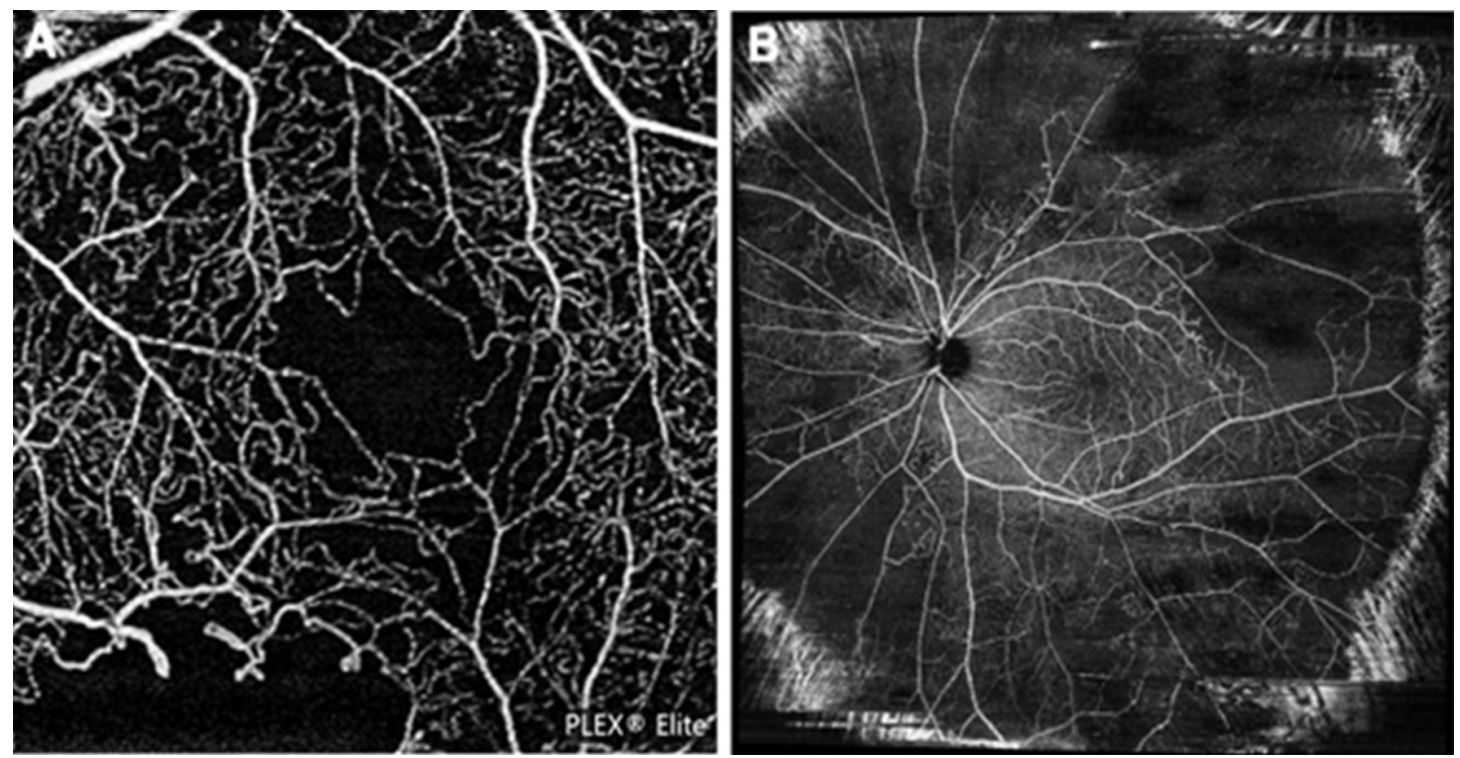

Fig. 2. Consensus was achieved on using the manufacturer's software to measure areas of decreased retinal flow signal on traditional OCTA, and near consensus was reached on using the percentage of decreased flow area in wide-field OCT angiography (OCTA). A 3 $\times$ 3-mm superficial plexus OCTA scan centered on the fovea (A) and a wide-field superficial retinal plexus OCTA scan (B) $90^{\circ}$ of FOV showing areas of decreased retinal flow

wide-field OCTA should be measured by percentage of decreased flow area and not by number of affected subfields. A consensus was reached among the experts group ( $62.5 \%$ vs. $50 \%$ of users group) that a large flow decrease should be defined as $\geq 30 \%$ of the total wide-field area (Table 1 and 2). Some $43.75 \%$ of the users group believed that it should be defined as $\geq 10 \%$ (Fig 2 ).

\section{TERMinOLOGY AND NOMENCLATURE OF DE- CREASED VASCULAR Flow ON CONVENTION- AL AND WIDE-FIELD OCTA}

Most participants (83.53\%) agreed that it would be necessary to distinguish the cause of reduced flow in retinal vascular diseases. They suggested that, besides artifacts, reduced flow signal in retinal vascular disease may arise from (1) inadequate blood supply causing capillary nonperfusion and ischemia (users group: 94.44\%; experts group: 90.32\%); (2) blockage due to hemorrhage or hard exudates (users group: 50\%; experts group: 70.97\%); (3) displacement of vessels due to cystoid macular edema (CME, users group: 61.11\%; experts group: 67.74\%) (Table 1); and (4) decreased or slow flow in microaneurysms (users group: 59.26\%; experts group: 90.32\%) (Table 1). However, there was no consensus on which terms should be specifically used.
Decreased flow signal of unknown origin: Some $21.18 \%$ of the respondents preferred the term "nondetectable flow signal" to describe a flow decrease of unknown origin, and 18.82\% preferred the term "flow decrease." There was no difference between the users group $20.37 \%$ and $20.37 \%$, respectively) and the experts group (22.58\% and $16.13 \%$, respectively).

Decreased flow signal due to CME: Some $16.67 \%$ of the participants preferred the term "nondetectable flow signal," and $14.29 \%$ of the participants liked the suggested terms "flow attenuation" and "flow void" to describe decrease in flow signal caused by vessel displacement in the presence of CME. Some $19.35 \%$ of the experts group chose the term "flow impairment."

Decreased flow signal due to signal blockage: Some $41.94 \%$ of the experts group and $31.48 \%$ of the users group deemed the suggested term "nondetectable flow signal" as most suitable to describe decreased flow signal in the presence of hemorrhage or hard exudates. Some $25.81 \%$ of the experts group and $29.63 \%$ of the users group favored the term "signal void."

Decreased flow signal due to slow flow: Preferred terms to describe flow decrease due to microaneurysms were "flow decrease" $(27.78 \%$ of the users group) and "flow impairment" (25.81\% of the experts group). 
Table 1. Questions for which a Co-agreement Was Achieved between the "Users" Group and the OCTA "Experts" Group

\begin{tabular}{|c|c|c|c|}
\hline Item No. & Question & $\begin{array}{l}\text { Survey Response OCTA Users } \\
\text { Group }(\mathrm{n}=54)(\%)\end{array}$ & $\begin{array}{l}\text { Survey Response OCTA Experts } \\
\text { Group }(n=31)(\%)\end{array}$ \\
\hline 8 & $\begin{array}{l}\text { Do you consider it necessary to distinguish } \\
\text { cause of decreased vascular flow in retinal } \\
\text { vascular diseases? }\end{array}$ & Yes $83.87 \%$ & Yes $83.33 \%$ \\
\hline 9 & $\begin{array}{l}\text { Decreased vascular OCTA flow in diabetes } \\
\text { can be secondary to }\end{array}$ & $\begin{array}{l}\text { Ischemia } 94.44 \% \\
\text { Displacement of vessels } 61.11 \%\end{array}$ & $\begin{array}{l}\text { Ischemia } 90.32 \% \\
\text { Displacement of vessels } 67.74 \%\end{array}$ \\
\hline 23 & $\begin{array}{l}\text { Do you think today OCTA should be } \\
\text { implemented in identification and severity } \\
\text { staging of DR? }\end{array}$ & Yes $72.22 \%$ & Yes $83.87 \%$ \\
\hline 24 & $\begin{array}{l}\text { Parameters that should be used to identify } \\
\text { and stage severity of DR }\end{array}$ & $\begin{array}{l}\text { The presence of NV } 84.62 \% \\
\text { FAZ parameters } 74.36 \% \\
\text { Presence and amount of no flow } \\
\text { areas } 74.36 \%\end{array}$ & $\begin{array}{l}\text { The presence of NV } 73.08 \% \\
\text { FAZ parameters } 69.23 \% \\
\text { Presence and amount of no flow } \\
\text { areas } 76.92 \%\end{array}$ \\
\hline 25 & $\begin{array}{l}\text { Do you think OCTA can be used in } \\
\text { identification and staging of DMI? }\end{array}$ & Yes $88.89 \%$ & Yes $93.55 \%$ \\
\hline 27 & $\begin{array}{l}\text { Should/can ischemic vs. nonischemic RVO } \\
\text { be defined based on wide-field OCTA? }\end{array}$ & Yes $85.19 \%$ & Yes $83.87 \%$ \\
\hline
\end{tabular}

DMI = diabetic macular ischemia; DR = diabetic retinopathy; FAZ = foveal avascular zone; NV = neovascularization; NVD = neovascularization at the disc; OCTA = OCT angiography; RVO = retinal vein occlusion.

Table 2. Consensus Levels of Main Topics of OCTA Nomenclature Survey

\begin{tabular}{|c|c|}
\hline $\begin{array}{l}\text { Item } \\
\text { No. }\end{array}$ & Consensus Level \\
\hline & Consensus \\
\hline 3 & The International Wide-field Imaging Study Group definition of wide-field does not apply to OCTA (users group) \\
\hline 8 & The necessity to distinguish cause of decreased vascular flow in retinal vascular diseases (both groups) \\
\hline 9 & Causes of decreased vascular OCTA flow in retinal vascular diseases (both groups) \\
\hline 10 & $\begin{array}{l}\text { Automated inbuilt software shall be used to quantify and report the area of decreased vascular flow on OCTA } \\
\text { (experts group) }\end{array}$ \\
\hline 16 & If $\%$ is used, then $\geq 30 \%$ shall define an area of large flow decrease (experts group) \\
\hline 18 & $\begin{array}{l}\text { The necessity to apply different terms to describe OCTA vascular flow decrease due to different causes? (experts } \\
\text { group) }\end{array}$ \\
\hline 23 & OCTA should be implemented in the identification and severity staging of DR? (both groups) \\
\hline 24 & $\begin{array}{l}\text { Presence of NV and area of nonperfusion and FAZ parameters shall be implemented in identification and severity } \\
\text { staging of DR (both groups) }\end{array}$ \\
\hline 25 & OCTA can be used in identification and staging of DMI (both groups) \\
\hline 27 & Ischemic vs. nonischemic RVO can be defined on the basis of wide-field OCTA (both groups) \\
\hline \multirow[t]{2}{*}{32} & The OCTA ILM/vitreous slab should be preferably used to detect NVE/NVD (experts group) \\
\hline & Near Consensus \\
\hline 4 & Parameter, wide-field OCTA definition should be based on (users group) \\
\hline 6 & The degrees of field of view (FOV) to define "wide-field OCTA" (experts group) \\
\hline 11 & $\begin{array}{l}\text { A large area of decreased flow on conventional OCTA should be }>0.15 \mathrm{~mm} 2,>0.3 \mathrm{~mm} 2 \text {, or } 0.5 \mathrm{~mm} 2 \text { ? (both } \\
\text { groups) }\end{array}$ \\
\hline 14 & $\begin{array}{l}\text { The easiest way to quantify and report the size of decreased vascular flow on wide-field OCTA for peripheral flow } \\
\text { decrease (both groups) }\end{array}$ \\
\hline 28 & The parameter to define ischemic RVO based on wide-field OCTA (users group) \\
\hline
\end{tabular}




\begin{tabular}{|c|l|}
\hline & No Consensus \\
\hline 19 & The term to describe flow decrease in SCP, DCP of unknown origin \\
\hline 20 & The term to describe flow decrease in SCP, DCP due to vessels displacement by CME \\
\hline 21 & The term to describe OCTA vascular flow decrease due to signal blockage/shadowing \\
\hline 22 & The term to describe OCTA vascular flow decrease due to slow flow \\
\hline 26 & The way to define and quantify DMI \\
\hline 30 & The percentage of decrease flow area to define ischemic vs. nonischemic RVO in wide-field OCTA images \\
\hline
\end{tabular}

$\mathrm{CME}$ = cystoid macular edema; DCP = deep capillary plexus; DMI = diabetic macular ischemia; DR = diabetic retinopathy; FAZ = foveal avascular zone; ILM = internal limiting membrane; NVD = neovascularization at the disc; NVE = neovascularization elsewhere; OCTA = OCT angiography; RVO = retinal vein occlusion; SCP = superficial capillary plexus. Consensus was defined by an agreement of $\geq 60 \%$ in the experts group or the users group. Near consensus was defined by an agreement of $51 \%$ to $60 \%$ in the experts group or the users group. No consensus was defined by a $<51 \%$ agreement in both groups. The referring group is provided in parentheses

Definition of NVE/NVD: There was consensus in the experts group (70.94\%) that NVE or NVD should be described as "supraretinal flow with breaching of internal limiting membrane (ILM) on OCTA cross-section scan and as a dense, irregular and convoluted network of vessels visible on ILMvitreous and superficial slabs on en face OCTA" according to medical retinal consensus (Table 2). Some $57.41 \%$ of the users group believed that only the ILM/vitreous slab should be used to detect NVE/NVD, and $33.33 \%$ of them suggested using any slab that depicts the NV (Fig 3).

\section{OCTA in Retinal Vascular Disease MaN- AGEMENT AND STAGING}

\section{Diabetic Retinopathy}

The majority of respondents $(76.47 \%)$ agreed that OCTA should be implemented in identification and staging of severity of DR (Table 1).

There was consensus that the parameters "the presence of NV" (experts group: 73.08\%; users group: 84.62\%), "the FAZ parameters" (experts group: 69.23\%; users group: $74.36 \%$ ), and "the presence and amount of no flow areas" (experts group: $76.92 \%$; users group: $74.36 \%$ ) should be added for the staging and classification of DR. In addition, the users group also suggested that the presence of microaneurysms (64.1\%), the number of intraretinal microvascular abnormalities (79.49\%), and the vessel density in the superficial capillary plexus $(61.54 \%)$ and the deep capillary plexus $(66.67 \%)$ seen on OCTA should be included to grade the severity of DR (Table 1 ).

Diabetic macular ischemia (DMI) is characterized by the occlusion and loss of the macular capillary network. Almost all of the participants $(90.59 \%)$ believe that OCTA is an indispensable modality for the staging of DMI (Table 1). However, there was no agreement on the most suitable parameters: No consensus was reached among the participants. Some $38.96 \%$ chose "the FAZ size," and $37.66 \%$ suggested "the perifoveal vessel density" to define and quantify DMI (Table 2).
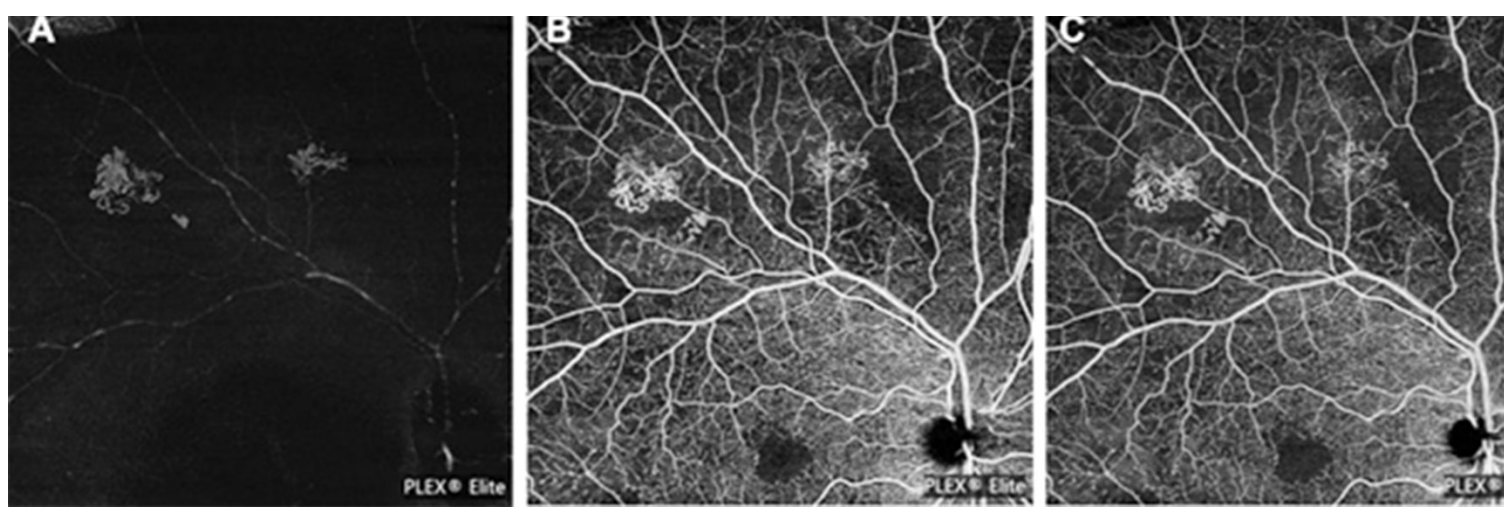

Fig. 3. Examples of retinal neovascularization (NV) visible on different OCT angiography (OCTA) slabs. A, OCTA internal limiting membrane (ILM)/vitreous slab. B, OCTA superficial capillary plexus slab. C, OCTA whole retinal slab 


\section{Retinal Vein Occlusion}

Most of the participants (84.71\%) agreed that ischemic versus nonischemic retinal vein occlusion (RVO) can be defined via wide-field OCTA. Some $56.52 \%$ of the users group and $46.15 \%$ of the experts group preferred "percentage of decreased flow areas in the wide-field OCTA image compared to total area" to define ischemic versus nonischemic RVO. Furthermore, no consensus was achieved on what percentage should be used to define ischemic versus nonischemic RVO (Table 2). Some $50 \%$ of the experts group and $34.62 \%$ of the users group believed that the area of decreased flow on widefield OCTA should be $\geq 30 \%$ of absolute area to define ischemic RVO. Some $36.96 \%$ of the users group and $30.77 \%$ of the experts group suggested "nonflow or decreased flow area" based on optic nerve head $(\mathrm{ONH})$ area equivalents as the most suitable parameter to assess ischemic versus nonischemic RVO. Among them, $62.5 \%$ of the experts group recommended that ischemic RVO should be diagnosed in the presence of " $\geq 10 \mathrm{ONH}$ area equivalents."

\section{Artifacts}

A consensus was reached in the experts group $(68.97 \%$ to $100 \%$, depending on individual proposed artifact terms) and the users group (52.94\% to $94.12 \%$ ) with respect to the description of OCTA artifacts. The terminology proposed by the medical retina community for normal retina should be applied for retinal vascular diseases as well.

\section{No Consensus}

Important points for which no consensus was reached in the experts or the users group (Table 2) included the parameter for defining wide-field OCTA, the term used to describe flow decrease caused by various causes, the simplest way to define and quantify DMI, and the way to define ischemic RVO based on wide-field OCTA.

\section{Discussion}

Based on the current OCTA terminology found in the literature, we created an online survey and distributed it among specialists in the field of retinal vascular diseases. The purpose was to explore the application and use of the OCTA nomenclature, with the final goal to standardize OCTA nomenclature in the field of retinal vascular diseases.
OCTA can image the vascular structures of the retina by capturing high-resolution 2-dimensional images of different layers of the retina using low coherence interferometry. This makes the OCTA an essential tool for detecting and monitoring abnormal flow in retinal vascular diseases [3, 8]. OCTA is dye-free and therefore bypasses dye leakage that limits our ability to evaluate capillary perfusion. With the help of OCTA, it is now possible to visualize vascular features in different retinal layers [5]. This makes OCTA an ideal approach for the assessment of various retinal vascular diseases such as DR, RVO, and retinal artery occlusion. There is no doubt that the evaluation of the morphology and quantitative assessment of vascular changes can help us improve our understanding of the pathological and physiologic processes, determine the disease's activity and severity, and provide appropriate treatment and management of retinal vascular diseases. As a result, various clinical studies and publications focus on OCTA findings for the assessment of the pathophysiology, prediction, diagnosis, severity, response to therapies, and follow-up of retinal vascular diseases $[7,8,9,10]$. With an increasing number of publications in this field, different OCTA parameters are implemented, and there is a growing divergence in the use of terms to describe qualitative and quantitative changes on OCTA.

\section{WIDE-FIELD OCTA}

Although conventional $3 \times 3-\mathrm{mm}$ and $6 \times 6$ $\mathrm{mm}$ images produce high-resolution images allowing accurate assessment of the macular capillaries and vasculature, images of $9 \times 9 \mathrm{~mm}$ to 15 $\times 15 \mathrm{~mm}$ allow the assessment of a larger retinal area but trade the wider FOV for resolution [41]. To assess the vasculature beyond the vascular arcades with OCTA using currently available devices, montage methods are used, which stitch several individual OCTA images automatically together Prototypes capturing up to 100 degree FOV at once have been developed as well [3].

The term "wide-field" OCTA is heterogeneously used for a single $12 \times 12 \mathrm{~mm}$ OCTA scan, 4 and montage scans consist of two $15 \times 9$-mm scans, 4 five $12 \times 12$-mm scans, 5 two $12 \times 12$-mm scans, 6 four $12 \times 12$-mm scans, five $6 \times 10$-mm scans, or 
five $9 \times 9$-mm scans [2]. All of these images are capturing different FOVs. The term "ultra-widefield OCTA" was introduced to describe $100^{\circ}$ OCTA images consisting of a $4 \times 4$ grid of 16 individual $6 \times 6-\mathrm{mm} 2$ scans. A consensus was reached in the users group in our survey that OCTA cannot visualize the vortex veins, and the Classification and Guidelines for Wide-field Imaging cannot be applied to OCTA in retinal vascular diseases [9]. This is in line with the results of the standardization approach in uveitic OCTA nomenclature Unfortunately, no consensus was achieved in our survey on which parameter the wide-field definition should be based; however, the parameter FOV was favored (near consensus). Field of view $\geq 70$ degrees was the mutually agreed area and parameter in our previous uveitis survey, which should define wide-field OCTA [8].

\section{Measurement and Terms of Decreased Flow Signal}

Different methods have been used to measure areas of decreased flow on OCTA in retinal vascular diseases. Tan et al. [14] used a custom MATLAB algorithm to calculate retinal perfusion density, capillary perfusion density, and capillary dropout density in DR using $12 \times 12$-mm OCTA scans. Seknazi et al. [40] used the AngioAnalytics software to binarize and calculate the relative density of flow as a percentage of the total area. They ordinally graded capillary dropout on OCTA slabs ranging from 0 to 8 ( 0 being no capillary dropout, and 8 being extensive capillary dropout). Kim et al. [8] used a custom semiautomated algorithm to assess skeleton density, vessel density, fractal dimension, and vessel diameter index. To convert OCTA into binary images, a 3-step method consisting of a global threshold, hessian filter, and adaptive threshold in MATLAB was used. These examples demonstrate the necessity of a standardized procedure in measuring areas of reduced flow on OCTA in retinal vascular disease. A consensus was obtained in our survey that the manufacturer software should be used to measure areas of decreased flow on OCTA, and a near consensus was reached that a large area of decreased flow should be defined by an area of $\geq 0.5 \mathrm{~mm}^{2}$. This consensus comes with a couple of challenges and limitations because the manufacturer software solutions of the different OCTA modules only allow the assessment of arbitrary parameters. In addition, OCTA images beyond 6 $\times 6 \mathrm{~mm}$ are usually not quantifiable at all. The FAZ area is so far the only parameter that can be assessed on all devices; however, the comparability of FAZ measures is limited given the divergent segmentation methods (and of course the different underlying methods generating the flow motion contrast images). A near consensus was achieved that the size and amount of decreased vascular flow on wide-field OCTA should be reported in percentage of decreased flow area compared with the whole area. The respondents agreed that $\geq 30 \%$ of the affected area should be considered a "large flow decrease" on wide-field OCTA. This measure was favored over the assessment of affected subfields, which has been regularly used in wide-field OCTA studies [9].

There was strong consensus that different terms should be applied to account for the different possible underlying causes of decreased flow signal. Possible underlying mechanisms were accepted to be decreased flow signal of unknown origin, inadequate blood supply causing ischemia, blockage due to hemorrhage or hard exudates, displacement of vessels due to macular edema, and decreased/slow flow in microvascular abnormalities such as microaneurysms. Various terms such as "grayish areas," "no-flow areas," "areas with decreased vascular perfusion," "flow deficit," "flow impairment," "reduced flow," "flow abnormalities," and "flow void" have been noted in publications to describe OCTA signal attenuation secondary to various mechanisms. It was previously also recommended not to use the term "nonperfusion," because it is possible that in areas of absent flow signal, the blood flow is just below the threshold of detection.Unfortunately, there was not a single consensus on what terms should be preferably applied for the individual reasons of reduced OCTA signal.

\section{Staging of Disease SeVerity}

There was unanimous agreement in our survey between the experts group and the users group that OCTA imaging should be implemented in the identification and staging of the severity of DR. The FAZ parameters, the presence of NV visible on OCTA, and the presence and amount of no 
flow areas should be integrated in a new staging system. This is in line with previous studies highlighting the strong correlation of FAZ parameters with the severity of DR.8, It indicates the strong need for an updated severity assessment including other image modalities such as wide-field imaging, wide-field fluorescein angiography, and OCTA, and parameters such as ischemia and presence of capillary nonperfusion probably beyond the conventional, gold standard Early Treatment Diabetic Retinopathy Study 7-field color fundus imaging.

Until now, the definition of ischemic RVO is disputable. The most used parameter in the literature has been the area of nonperfusion visible on fluorescein angiography, which was most frequently measured by the $\mathrm{ONH}$ area equivalents. An equivalent of $\geq 10 \mathrm{ONH}$ areas was frequently used; however, other thresholds ranging from $\geq 5$ to $\geq 30$ were applied as well. There was consensus among the users that the differentiation of ischemic versus nonischemic RVO can be made on the basis of wide-field OCTA. However, there was only near consensus that the percentage of decreased flow areas in the wide-field OCTA image compared with total area should be used as an assessment parameter. Some $50 \%$ agreed that an area of $\geq$ $30 \%$ would define ischemic RVO. Only approximately $35 \%$ of the users and experts suggested ONH equivalents as a suitable tool to differentiate these 2 conditions. The majority choosing this parameter agreed that $\geq 10 \mathrm{ONH}$ equivalents of decreased/absent flow signal (as in many previous FA studies) would indicate an ischemic RVO.

\section{Artifact Assessment}

A consensus was reached in the expert group and the user group that the so far proposed artifact terminology by the medical retina community for normal retina can and should be applied. The terms "motion, projection, segmentation, and shadowing artifacts" should be used to describe potential imaging errors. This is in line with the results of the uveitis nomenclature survey.

\section{Conclusions}

Our intention is to standardize the heterogeneously used OCTA nomenclature in retinal vascular diseases. The first step was this survey presented. A potential limitation of the survey may be that because of the anonymity, the information provided by the respondents regarding the number of publications and therefore their status of expert versus users could not be verified. However, we also note that respondents had no obvious incentive to misrepresent their experience in such an anonymous survey. Encouragingly, in some areas and topics, consensus could already be achieved. However, it also highlights many discrepancies and discordance among retina specialists, OCTA users, and OCTA experts. Our first results have illustrated that further expert discussion is needed to establish a standardized terminology for the use of OCTA in retinal vascular diseases. These areas include (among others) the definition of wide-field OCTA, the terms used to describe flow decrease induced by various causes, the simplest way to define and quantify DMI, and the way to define ischemic RVO based on wide-field OCTA. The results further highlight the need for at least a few parameters that can be automatically and homogeneously assessed by all OCTA modules, similar to central macular thickness or retinal volume on structural OCTs. Manufacturers should be obligated to implement software that allows the homogenous assessment of respective parameters across all OCT machines. These results form the basis for the development of an appropriate nomenclature via a Delphi approach among a smaller expert group in OCTA and retinal vascular diseases, which is currently ongoing.

\section{REFERENCES}

1. Zhang Q, Lee CS, Chao J et al. Wide-field optical coherence tomography based microangiography for retinal imaging. Sci Rep. 2016;6:22017.

2. Chalam KV, Sambhav K. Optical coherence tomography angiography in retinal diseases. J Ophthalmic Vis Res. 2016;11:84e92.

3. Dodo Y, Suzuma K, Ishihara K et al. Clinical relevance of reduced decorrelation signals in the diabetic inner choroid on optical coherence tomography angiography. Sci Rep. 2017;7:5227.

4. Nesper PL, Scarinci F, Fawzi AA. Adaptive optics reveals photoreceptor abnormalities in diabetic macular ischemia. PloS One. 2017;12:e0169926.

5. Tian M, Wolf S, Munk MR, Schaal KB. Evaluation of different swept-source optical coherence tomography angiography (SS-OCTA) slabs for the 
detection of features of diabetic retinopathy. Acta Ophthalmol. 2020;98: e416ee420.

6. Kashani AH, Lee SY, Moshfeghi A et al. Optical coherence tomography angiography of retinal venous occlusion. Retina. 2015;35:2323e2331.

7. Kashani A, Zhang Y, Capone A et al. Impaired retinal perfusion resulting from vitreoretinal traction: a mechanism of retinal vascular insufficiency. Ophthalmic Surg Lasers Imaging Retina. 2016;47:8.

8. Kim AY, Chu Z, Shahidzadeh A et al. Quantifying microvascular density and morphology in diabetic retinopathy using spectral-domain optical coherence tomography angiography. Invest Ophthalmol Vis Sci. 2016;57:0CT362e0CT370.

9. Dansingani $K K$, Inoue $M$, Engelbert $M$, Freund KB. Optical coherence tomographic angiography shows reduced deep capillary flow in paracentral acute middle maculopathy. Eye. 2015;29:1620e1624.

10. Rochepeau C, Kodjikian L, Garcia M-A et al. Optical coherence tomography angiography quantitative assessment of choriocapillaris blood flow in central serous chorioretinopathy. Am J Ophthalmol. 2018;194:26e34.

11. Chou BW, Nesper PL, Jampol LM, Mirza RG. Solitary retinal hemangioblastoma findings in OCTA pre- and post-laser therapy. Am J Ophthalmol Case Rep. 2018;10:59e61.

12. Bhavsar KV, Jia Y, Wang J et al. Projection-resolved optical coherence tomography angiography exhibiting early flow prior to clinically observed retinal angiomatous proliferation. Am J Ophthalmol Case Rep. 2017;8:53e57.

13. Kaizu Y, Nakao S, Arima M et al. Flow density in optical coherence tomography angiography is useful for retinopathy diagnosis in diabetic patients. Sci Rep. 2019;9:8668.

14. Tan B, Chua J, Lin E et al. Quantitative microvascular analysis with wide-field optical coherence tomography angiography in eyes with diabetic retinopathy. JAMA Netw Open. 2020;3:e1919469.

15. You QS, Chan JCH, Ng ALK et al. Macular vessel density measured with optical coherence tomography angiography and its associations in a large population-based study. Invest Ophthalmol Vis Sci. 2019;60:4830e4837.

16. Mastropasqua R, Toto L, Mastropasqua A et al. Foveal avascular zone area and parafoveal vessel density measurements in different stages of diabetic retinopathy by optical coherence tomography angiography. Int J Ophthalmol. 2017;10:1545e1551.

17. Ishibazawa A, Nagaoka T, Takahashi A et al. Optical coherence tomography angiography in diabetic retinopathy: a prospective pilot study. Am J Ophthalmol. 2015;160:35e44 e31.
18. Sim DA, Keane PA, Fung S et al. Quantitative analysis of diabetic macular ischemia using optical coherence tomography. Invest Ophthalmol Vis Sci. 2014;55:417e423.

19. Hwang TS, Jia Y, Gao SS et al. Optical coherence tomography angiography features of diabetic retinopathy. Retina. 2015;35:2371e2376.

20. Alam M, Zhang Y, Lim JI et al. Quantitative optical coherence tomography angiography features for objective classification and staging of diabetic retinopathy. Retina. 2020;40:322e332.

21. Agemy SA, Scripsema NK, Shah CM et al. Retinal vascular perfusion density mapping using optical coherence tomography angiography in normals and diabetic retinopathy patients. Retina. 2015;35:2353e2363.

22. Cui Y, Zhu Y, Wang JC et al. Imaging artifacts and segmentation errors with wide-field sweptsource optical coherence tomography angiography in diabetic retinopathy. Transl Vis Sci Technol. 2019;8:18.

23. Bonnin S, Krivosic V, Cognat E, Tadayoni R. Visibility of blood flow on optical coherence tomography angiography in a case of branch retinal artery occlusion. J Ophthalmic Vis Res. 2018;13:75e77.

24. Al-khersan H, Russell JF, Shi Y et al. Wide field swept source OCT angiography of multifocal retinal and choroidal occlusions from embolic triamcinolone acetonide. Am J Ophthalmol Case Rep. 2020;18:100704.

25. Tian M, Tappeiner C, Zinkernagel MS et al. Evaluation of vascular changes in intermediate uveitis and retinal vasculitis using swept-source widefield optical coherence tomography angiography. Br J Ophthalmol. 2019;103:1289e1295.

26. Spaide RF, Fujimoto JG, Waheed NK et al. Optical coherence tomography angiography. Prog Retin Eye Res. 2018;64:1e55.

27. Wei X, You Q, Camino A et al. Comparison of OCTA algorithms for detecting vascular and nonvascular flow signal on hyperreflective lesions in diabetic retinopathy. Invest Ophthalmol Vis Sci. 2019;60, 147-147.

28. Pichi F, Salas EC, de Smet MD et al. Standardisation of optical coherence tomography angiography nomenclature in uveitis: first survey results. Br J Ophthalmol. Jul 292020 [Epub ahead of print].

29. Choudhry N, Duker JS, Freund KB et al. Classification and guidelines for widefield imaging: recommendations from the International Widefield Imaging Study Group. Ophthalmol Retina. 2019;3:843e849.

30. Arya M, Sorour O, Chaudhri J et al. Distinguishing intraretinal microvascular abnormalities from retinal neovascularization using optical coherence tomography angiography. Retina. 2020;40:1686e1695. 
31. Hirano T, Hoshiyama K, Hirabayashi K et al. Vitreoretinal interface slab in OCT angiography for detecting diabetic retinal neovascularization. Ophthalmol Retina. 2020;4:588e594.

32. Spaide RF, Fujimoto JG, Waheed NK. Image artifacts in optical coherence tomography angiography. Retina. 2015;35:2163e2180.

33. McMillan SS, King M, Tully MP. How to use the nominal group and Delphi techniques. Int J Clin Pharm. 2016;38:655e662.

34. Sorour 0, Arya M, Waheed N. New findings and challenges in OCT angiography for diabetic retinopathy. Ann Eye Sci. 2018;3:44.
35. Tey KY, Teo K, Tan ACS et al. Optical coherence tomography angiography in diabetic retinopathy: a review of current applications. Eye Vis. 2019;6:37.

36. 36. Tan ACS, Tan GS, Denniston AK et al. An overview of the clinical applications of optical coherence tomography angiography. Eye. 2018;32:262e286.

37. Nesper PL, Roberts PK, Onishi AC et al. Quantifying microvascular abnormalities with increasing severity of diabetic retinopathy using optical coherence tomography angiography. Invest Ophthalmol Vis Sci. 2017;58:BIO307eBI0315. 